\title{
RESIDÊNCIA MÉDICA SOB A ÓPTICA DO DIREITO DO TRABALHO
}

\section{Armênio Matias Corrêa Lima}

Resumo: A residência médica é a principal forma de aperfeiçoamento profissional em medicina ${ }^{1}$. É um período de pelo menos dois anos de atividade clínica intensa, acompanhada de considerável carga de responsabilidade. De acordo com a legislação e com a jurisprudência brasileiras, porém, os médicos residentes são considerados estudantes, não trabalhadores. Os litígios e as questões jurídicas pertinentes à residência médica não são, portanto, de competência da Justiça do Trabalho. Por outro lado, vários direitos básicos equivalentes aos trabalhistas são garantidos aos residentes. A legislação que rege a residência médica assegura aos residentes: um dia de repouso por semana, trinta dias consecutivos de repouso por ano, filiação à previdência social e os direitos decorrentes do seguro de acidentes do trabalho; à médica residente gestante é dado licença com continuidade da bolsa pelo período de quatro meses. Dados tais precedentes, outros direitos dessa natureza podem no futuro ser também estendidos ao residente, tais como indenização por acidentes de trabalho, o reconhecimento da insalubridade ocupacional, o direito a

1 Aluno da Escola Superior da Magistratura do Estado de Santa Catarina (ESMESC). Graduação em Ciências Jurídicas e Sociais (1985) e em Medicina (1988) pela Universidade Federal do Rio Grande do Sul (UFRGS), especialização em Medicina do Trabalho (UFRGS, 1990) e em Direito do Trabalho (Univali/AMATRA12, 2008), mestrado em Community Health in Developing Countries - Ruprecht Karls Universitaet Heidelberg (RKUH, 1994) e doutorado em Educação pela Universidade Federal de Santa Catarina (UFSC, 2003). Experiência médica clínica - especialidades de Medicina Geral Comunitária e de Homeopatia. E-mail: dr.lima@gmail.com 
licença-paternidade e a garantia de cumprimento do limite máximo de horas de atividade por semana.

Palavras-chave: Direito do trabalho. Competência jurisdicional. Residência médica. Educação médica. Direitos fundamentais.

\section{INTRODUÇÃO}

Este artigo foi desenvolvido no Curso de Especialização em Direito do Trabalho e Preparação para a Magistratura do Trabalho promovido conjuntamente pela Associação dos Magistrados do Trabalho da 12a Região e pela Universidade do Vale do Itajaí. Formação e experiência de Bacharel em Direito, aliadas às de médico que passou pelo processo de transformação - profissional, de personalidade, de concepção de mundo - resultado dos anos de residência médica, foram determinantes para o desenvolvimento deste projeto.

A residência médica é uma experiência de trabalho intenso, exaustivo, de privação de amenidades como lazer e descanso. A bem da verdade, a residência em medicina geral e comunitária, hoje denominada medicina de família e comunidade, é assaz amena, se comparada às mais convencionais residências médicas hospitalares. A própria carga horária de atividades era mais leve - por volta de 57 a 58 horas por semana, enquanto das residências hospitalares não ficavam em menos de 60 horas por semana. No caso das especialidades cirúrgicas, costumavam ultrapassar de 80 horas semanais. Enquanto a medicina comunitária é exercida majoritariamente em ambulatório e incluindo atividades educativas e preventivas externas, as especialidades hospitalares lidam mais habitualmente com pessoas com a saúde severamente comprometida e com a responsabilidade direta sobre as perspectivas de vida e de morte dessas pessoas.

O presente estudo utiliza a experiência adquirida pelo aprendizado típico de estágio prático na medicina como premissa 
inicial para fazer uma reflexão sobre a condição jurídica do médico residente. Esta reflexão iniciou ao cogitar propor enunciado para a $1^{\mathrm{a}}$ Jornada de Direito Material e Processual na Justiça do Trabalho (Brasília, 21-23.11.2007) com o seguinte teor:

A carga horária de atividade de 60 horas semanais previstas no artigo $5^{\circ}$ da Lei no $6.932 / 1981$ para os médicos residentes excede a disposição do inciso XIII do artigo 7º da Constituição Federal de 1988 de "duração do trabalho normal não superior a oito horas diárias e quarenta e quatro semanais [...]". Conforme esse entendimento, o referido dispositivo legal não pode ter sido recepcionado pela Constituição, em 1988.

Ocorre que a legislação e a jurisprudência brasileiras não consideram as atividades do médico ou médica residente como trabalho. Entendemos, no entanto, que o tema merece uma nova reflexão, motivo pelo qual foi escolhido para este trabalho de conclusão de curso. O questionamento que se propõe é: Podem os médicos residentes ter direitos trabalhistas? $\mathrm{O}$ que fundamenta esse posicionamento?

\section{HISTÓRICO DA RESIDÊNCIA MÉDICA}

Residência médica é uma modalidade de pós-graduação - tida como 'padrão ouro' de especialização médica - desenvolvida em treinamento. ${ }^{2}$ Em geral é feita logo em seguida à graduação, quase sempre em instituição hospitalar. Como observa Laura Feuerwerker que:

[...] é no processo de especialização, no treinamento prático que a residência propicia, que se dá a verdadeira "iniciação profissional" do médico. Tanto que, para a inserção no mercado de trabalho, é mais importante e significativa a instituição onde

2 FEUERWERKER, Laura Camargo Macruz; SENA, Roseni R . Contribuição ao movimento de mudança na formação dos profissionais de saúde: uma avaliação das experiências UNI. Interface: Comunicação, Saúde e Educação, Botucatu, v. 6, n. 10, p. 37-50, 2002, p. 61. 
os médicos fizeram seu processo de especialização do que a escola médica de origem. ${ }^{3}$

Em pesquisa sobre o perfil dos médicos brasileiros promovida pelo Conselho Federal de Medicina, 62\% dos médicos relatam terem feito residência médica. A maior parte (78\%) a fez em instituições públicas, principalmente na região Sudeste do Brasil (65\%). A predominância da residência como parte da formação profissional foi maior no Rio Grande do Sul (74\%), no Maranhão (70\%) e em Santa Catarina (68\%). ${ }^{4}$

A história da residência médica iniciou em Baltimore, EUA, no Hospital Johns Hopkins, na década de 1890. Seus principais idealizadores foram William Stewart Halsted, que criou a residência em cirurgia, e William Osler, que criou-a em medicina interna. Ambos defendiam que o aprendizado médico deve ser construído por meio da prática clínica. Como originalmente concebida, os médicos residiam no prédio da administração do Hospital, tinham dedicação integral ao serviço, e o tempo de residência não tinha prazo para conclusão. ${ }^{5}$

Em 1910, o estudo sobre as escolas médicas norte-americanas que veio a ser conhecido como Relatório Flexner ${ }^{6}$ consagrou a Johns Hopkins como modelo ideal de ensino. Escrito no momento de ascensão das formas de produção fordistas-taylorista, promoveu a divisão do conhecimento médico geral em especialidades e a fragmentação da prática em tarefas específicas, enfatizando o conhecimento gerado em laboratórios em detrimento das habilidades desenvolvidas com as vivências clínicas. As instituições financiadoras do ensino médico norte-americano

3 CARNEIRO, Mauro Brandão; GOUVEIA, Valdiney Veloso (coord.). O médico e o seu trabalho: aspectos metodológicos e resultados do Brasil. Brasília: Conselho Federal de Medicina, 2004: p. 55-56.

4 RAE, Angus. Osler vindicated: the ghost of Flexner laid to rest. Canadian Medical Association Journal, Ottawa, v. 164, n. 3, p. 1860-1861, (Jun. 26) 2001.

5 FLEXNER, Abraham. Medical education in the United States and Canada: a report to the Carnegie Foundation for the Advancement of Teaching. Bull 4. New York: The Carnegie Foundation; 1910.

6 KOIFMAN, Lilian. Crítica ao modelo biomédico na reformulação curricular do curso de medicina da Universidade Federal Fluminense. Rio de Janeiro, 1996. Dissertação (Mestrado), Escola Nacional de Saúde Pública. 
adotaram as recomendações de Abraham Flexner, transformando gradualmente o ensino e a prática médica norte-americana no que hoje é denominado modelo biomédico de atenção à saúde. ${ }^{7}$

A formação em residência desenvolvida em especialidade médica difundiu-se com o modelo biomédico, por toda América do Norte até a Segunda Grande Guerra e, após a Guerra, pela América Latina e pelo resto do mundo. No Brasil, as primeiras residências médicas foram implantadas no Hospital das Clínicas da Faculdade de Medicina da Universidade de São Paulo, em 1944, e no Hospital dos Servidores do Rio de Janeiro, em 1948. Nas décadas de 1960 e 1970, com o aumento tanto do número de escolas médicas como de hospitais, multiplicaram-se também os programas de residência médica. ${ }^{8}$

Em 1977, após continuada mobilização dos médicos residentes, o Decreto no 80.281 regulamentou a residência médica como curso de especialização com um ano de duração e criou a Comissão Nacional de Residência Médica (CNRM). Em 1981, com a Lei no 6.732/1981, a residência médica brasileira ganhou contornos definitivos, com duração de pelo menos dois anos.

\section{FUNCIONAMENTO DA RESIDÊNCIA MÉDICA}

A legislação brasileira prevê supervisão constante para as atividades do médico ou da médica residente. Na prática, a residência médica exige dos seus participantes trabalho braçal, independente e, as vezes improvisado. Neste ponto, ao invés de narrar nossa experiência pessoal sobre a residência, passamos a

7 FRAGA Filho, Clementino. Ensino médico no Brasil: análise crítica. Arquivos de Gastroenterologia, São Paulo, v. 25, n. especial, p. 26-31, 1988.

8 McKUSICK, Victor A. Foreword. In: NILSSON, Kent R.; PICCINI, Jonathan. The Osler Medical Handbook / Osler Medical Service, Johns Hopkins Hospital. 2. ed. Philadelphia: Elsevier, 2006: p. ix:

From the beginning, major responsibility for the care of the patients was given to the resident staff. The graduated residency made this possible, with juniors learning from their seniors. It may not be facetious to suggest that the traditionally strong and independent character of the Osler Medical Service's residency program can be traced in part to the hot Baltimore summers. By the end of June most faculty had departed for cooler climates. 
referir-nos a algumas descrições expostas na literatura do setor de saúde.

Halsted enfatizava que o treinamento médico deve ser feito sob constante supervisão de profissionais experimentados. No entanto, a residência médica tem funcionado desde seus primórdios como processo em que aprendizado resulta mais da dedicação intensiva e constante, possibilitada mais por um estilo de vida monástico e pelas parceiras de trabalho entre residentes novatos e veteranos do que de interação com os supervisores. Victor A. McKusick ex-médico-chefe do Hospital Johns Hopkins e ex-Diretor do Departamento de Medicina da Universidade Johns Hopkins escreve sobre a história da residência médica iniciada nessa instituição, que:

Desde o começo, a maior responsabilidade pelo cuidado dos pacientes foi dada à equipe de residentes. A residência graduada possibilitou isso, com novatos a aprender com seus veteranos. Pode não ser jocoso sugerir que o caráter tradicionalmente vigoroso e independente do programa de residência Serviço Médico Osler pode ser atribuído em parte aos verões quentes de Baltimore. No final de junho, a maioria dos docentes tinha partido para climas mais amenos. ${ }^{9}$

Adriana R. 1. Carro e colegas, em publicação conjunta do Ministério da Saúde e da Organização Pan-Americana de Saúde, consideram que a residência médica é uma instituição global que tem caráter "concomitantemente um processo de ensino, prática e pesquisa". ${ }^{10}$ Segundo eles, "A regulamentação da RM pelo Estado, e não pelas sociedades médicas [...] introduziu o médico residente como força de trabalho no sistema de saúde”

9 CARRO, Adriana Rosa Linhares; ARAÚJO, Aniara Nascimento Corrêa; OLIVEIRA Filho, Nosor Orlando de; SEIXAS, Paulo Henrique D`Ângelo. Residência médica: prioridades do Sistema Único de Saúde que determinam a distribuição de vagas. In: BARROS, André Falcão e col. (org.). Observatório de Recursos Humanos em Saúde no Brasil. Brasília: Ministério da Saúde \& OPAS, 2004: p. 226.

10 CARRO, Adriana Rosa Linhares; ARAÚJO, Aniara Nascimento Corrêa; OLIVEIRA Filho, Nosor Orlando de; SEIXAS, Paulo Henrique D Ângelo. Residência médica: prioridades do Sistema Único de Saúde que determinam a distribuição de vagas. In: BARROS, André Falcão e col. (org.). Observatório de Recursos Humanos em Saúde no Brasil. Brasília: Ministério da Saúde \& OPAS, 2004: p. 224. 
e os interesses das instituições hospitalares no desempenho de tarefas por parte dos residentes têm peso decisivo em com a residência médica tem se desenvolvido no Brasil. ${ }^{11}$

José H. L. Pessoa e Clóvis C. Constantino, docentes da Faculdade de Medicina de Jundiaí, apontam como o residente serve como mão-de-obra barata às instituições nas quais atuam. Para eles:

Considerando que a jornada de trabalho do médico residente é de 60 horas semanais, incluindo 24 horas de plantão, o conjunto dos residentes representa, para as instituições mantenedoras de programas de residência, uma importante força de trabalho. Os hospitais, públicos ou privados, esperam ansiosamente os médicos residentes, porque eles já se transformaram em peças fundamentais na rotina de suas atividades. Historicamente, são delegadas aos residentes inúmeras atribuições, que facilitam a dinâmica dos serviços. ${ }^{12}$

Prosseguem, exemplificando como, em termos práticos, o médico residente contribui para o funcionamento das instituições hospitalares nas quais atuam:

Para citar um exemplo, em ambulatórios pediátricos, sob a supervisão ou orientação do preceptor, o residente faz a história clínica, o exame físico, a solicitação de exames complementares, o contato com o laboratório e com o serviço de imagens, procura os especialistas ou cirurgiões quando necessário, orienta a família, redige a receita ou a hospitalização, se pertinente, preenche guias e papéis burocráticos e executa outras ações. ${ }^{13}$

11 PESSOA, José Hugo de Lins; CONSTANTINO, Clóvis Francisco. Revista da Sociedade de Cardiologia do Estado de São Paulo, São Paulo, v. 12, n. 6, p. 821-825, nov./dez., 2002: p. 822.

12 PESSOA, José Hugo de Lins; CONSTANTINO, Clóvis Francisco. Revista da Sociedade de Cardiologia do Estado de São Paulo, São Paulo, v. 12, n. 6, p. 821-825, nov./dez., 2002: p. 822.

13 MASSUDA, Adriano; CUNHA, Francisco Mogadouro da; PETTA, Helena. Residência médica: contribuições dos médicos residentes ao debate. Revista da Associação Médica Brasileira, São Paulo, p. 96-97, mar./apr. 2007, v. 53, n. 2: p. 96. 
A respeito da sobrecarga de trabalho, os médicos residentes Adriano Massuda, Francisco Cunha e Helena Petta relatam, em editorial para a Revista da Associação Médica Brasileira, que:

Ainda hoje há residentes submetidos a regimes de trabalho que ultrapassam 100 horas semanais [...] plantões de mais de 36 horas ininterruptas, muitas vezes sem supervisão adequada. Mais grave ainda é ser isso encarado por muitos com naturalidade ou, pior, como algo "necessário para o aprendizado". ${ }^{14}$

As atividades do médico residente geram-lhe responsabilidade civil como profissional médico, conforme afirmado tanto por doutrinadores jurídicos ${ }^{15},{ }^{16} \&{ }^{17}$ quanto por parecer do Conselho Federal de Medicina (CFM). Todos os atos do residente devem ser realizados sob supervisão de um preceptor responsável. Porém, como tem encargos de atuação com relativa autonomia, é pessoalmente imputável pelos seus atos profissionais. Nos termos do parecer do CFM:

É evidente que em se tratando de aprimoramento, o médico residente ao desempenharem suas atividades tem sobre si a responsabilidade pelos atos que pratica. [...] $\mathrm{O}$ médico residente apesar de toda a supervisão e orientação, conforme já enfocado, subtende-se que tenha os necessários conhecimentos para tratar da vida humana. Com efeito, o residente, ao prestar atendimento ao paciente, assume a responsabilidade direta pelos atos decor-

14 KFOURI Neto, Miguel. Culpa médica e ônus da prova: presunções, perda de uma chance, cargas probatórias dinâmicas. São Paulo: Revista dos Tribunais, 2002.

15 MORAES, Irany Novah. Erro médico e a justiça. 5. ed. São Paulo: Revista dos Tribunais, 2004.

16 SOUZA, Néri Tadeu Câmara. Responsabilidade civil e penal do médico. 2. ed. Campinas: LZN, 2006.

17 CONSELHO FEDERAL DE MEDICINA. Processo-Consulta CFM nº 0913/91. Responsabilidade ética do médico residente por atos médicos realizados. Relator: Cons. Hilário Lourenço de Freitas Júnior. Brasília: CFM, 08. nov. 1991 (Aprovado em sessão plenária dia 16.01.1992). Disponível em http://www.portalmedico.org.br/pareceres/cfm/1992/3_1992.htm, acesso em 06.07.2008. 
rentes, não podendo em hipótese alguma atribuir o insucesso a terceiros. ${ }^{18}$

Tendo em consideração as consideráveis atribuições que recaem sobre os médicos residentes, o Departamento de Psiquiatria da Universidade Federal de São Paulo (UNIFESP) criou em 2000 o Núcleo de Assistência e Pesquisa em Residência Médica (NAPREME) para apoiar os então 436 médicos residentes do complexo UNIFESP-EPM/HSP. De acordo com publicação do NAPREME na Internet:

O período de transição aluno-médico, a responsabilidade profissional, o isolamento social, a fadiga, a privação do sono, a sobrecarga de trabalho, o pavor de cometer erros e outros fatores inerentes ao treinamento estão associados a diversas expressões psicológicas, psicopatológicas e comportamentais que incluem: estados depressivos com ideação suicida, consumo excessivo de álcool, adição a drogas, raiva crônica e o desenvolvimento de um amargo ceticismo e um irônico humor negro. ${ }^{19}$

Para com Luiz Antonio Nogueira-Martins, coordenador do NAPREME/UNIFESP, e Miguel Roberto Jorge, os problemas mais significativos apontados na literatura sobre desgaste ocupacional na residência médica são a depressão e a privação de sono. A assim denominada 'síndrome do estresse do residente' tem como principais fatores causais a sobrecarga de trabalho, excessiva responsabilidade profissional e ambiente de trabalho marcado por competição e por mudanças freqüentes das suas condições. Segundo esses autores:

18 UNIFESP. Departamento de Psiquiatria. Núcleo de Assistência e Pesquisa em Residência Médica. Os fundamentos para a criação do serviço e o relato da experiência de um ano. São Paulo, UNIFESP, 23.10.2001. Disponível em: http:// www.unifesp.br/dpsiq/grupos/napreme.htm. Acesso em 13.07.2008.

19 NOGUEIRA-MARTINS, Luiz Antônio; JORGE, Miguel Roberto. Natureza e magnitude do estresse na Residência Médica. Revista da Associação Médica Brasileira, São Paulo, p. 28-34, jan./fev. 1998, v. 44, n. 1. 
A experiência com residência médica tem mostrado que os residentes são submetidos a diversos tipos de estresse durante o treinamento, e que estes fatores estressantes podem produzir efeitos danosos tanto para os residentes como para a qualidade da assistência por eles prestada aos pacientes. ${ }^{20}$

Portanto, em sua pós-graduação, o residente tem riscos e responsabilidades ocupacionais que não são de mero estudante, são riscos e responsabilidades próprios da profissão médica.

\section{NATUREZA JURÍDICA DA RESIDÊNCIA MÉDICA}

Durante as décadas de 1960 e 1970, com o aumento do número de programas de residência e, portanto de médicos residentes, estes se organizaram - em 1966 criaram a Associação Nacional dos Médicos Residentes (ANMR) - e se mobilizaram, demandando direitos. A legislação regulamentando a residência resultou em grande medida de tal mobilização.

No final da década de 1970, os médicos residentes reivindicaram também direitos trabalhistas. Heloisa Marques e Laura Rodrigues relatam a que chegou a ANMR no XII ${ }^{\circ}$ Congresso Nacional de Médicos Residentes em 1977 de que "escamotear o trabalho médico que ela [a residência médica] contém é permitir a exploração da mão-de-obra médica por preço aviltante" e que "o trabalho excessivo, mal remunerado e não regulamentado na residência médica prejudica o ensino." 21

Nesse ano, após três décadas de existência da residência médica no Brasil, o Decreto no 80.281/1977 regulamentou-a, definindo-a em seu artigo 10 como "modalidade do ensino de pós-graduação destinada a médicos, sob forma de curso de espe-

20 MARQUES, Heloisa Helena de Sousa; RODRIGUES, Laura Cunha. A luta pelos direitos trabalhistas dos médicos residentes. Pediatria, São Paulo, v. 1, p. 40-44, 1979.

21 BRASIL. Ministério da Educação e da Cultura. Portaria Interministerial $n^{\circ} 0722$, de 26 de julho de 1979. Brasília: Diário Oficial da União, 01.08.1979. Disponível em http://www.prolei.inep.gov.br/exibir.do;jsessionid=BF877F54B2B0F324E99B6 6815D221402?URI=http\%3A\%2F\%2Fwww.ufsm.br\%2Fcpd\%2Finep\%2Fprolei\% 2FDocumento\%2F6980781009708870151, acesso em 29.06.2008. 
cialização, caracterizada por treinamento em serviço, em regime de dedicação exclusiva [...]". O Decreto criou, no âmbito do Departamento de Assuntos Universitários do Ministério da Educação e da Cultura, a Comissão Nacional de Residência Médica (CNRM), com a função de credenciar e autorizar o funcionamento dos programas de residência médica. $\mathrm{O}$ parágrafo $2^{\circ}$ desse Decreto determinava duração mínima de um ano para a residência, com uma carga total de atividade de pelo menos 1.800 horas (ou seja, uma carga horária semanal de aproximadamente 40 horas).

Uma Portaria Interministerial que instituía um grupo de trabalho com o objetivo de "estudar e propor medidas legais visando à extensão dos direitos trabalhistas e previdenciários aos médicos residentes, sem descaracterizar os objetivos educacionais da Residência Médica” chegou a ser publicada em 1979.22 Em 1981, finalmente, a Lei no 6932 reformulou a residência médica, dando-lhe a estrutura atual. A definição do instituto, todavia, permaneceu a mesma, exceto pela dedicação exclusiva, que foi retirada. Esta lei, contudo, determina a duração de uma carga horária semana de 60 horas e estabelece um mínimo de $10 \%$ e um máximo de $20 \%$ da carga horária dedicada a atividades teórico-práticas.

Posteriormente a estas regulamentações, residentes ainda tentaram obter o reconhecimento de direitos trabalhistas. A jurisprudência brasileira, contudo, posicionou-se de maneira clara quanto às atividades da médica ou do médico residente não constituírem relação de trabalho. $O$ Tribunal Superior do Trabalho (TST), em três julgamentos de recursos de revista, consolidou tal posicionamento e manteve a jurisdição trabalhista afastada da residência médica.

No primeiro desses julgamentos, em 1984, a Primeira Turma do TST decidiu que:

A residência médica é uma forma de estágio de alto nível, sujeito a regime rigoroso compensado com uma ajuda de custo,

22 BRASÍLIA. Tribunal Superior do Trabalho. Recurso de Revista ${ }^{\circ} \mathbf{2 1 2 0}$ (Acórdão $n^{\circ}$ 3376). Relator: Min. Ildélio Martins. 24 set. 1984. D.J. 14.12.1984. 
como são as bolsas de estudo estrangeiras, o que descaracteriza a relação de emprego. ${ }^{23}$

Em 1986, a Primeira Turma do TST prolatou acórdão segundo o qual:

A Residência médica constitui um estágio de alto nível, uma modalidade de ensino necessária, conforme o Decreto $\mathrm{n}^{\circ} 80.281 / 77$, que regulamentou a atividade. E nos termos do referido texto legal e que não se abstrai que a relação entre o residente e a entidade hospitalar seja empregatícia, ao contrário, o fato de ser o residente contemplado com bolsas de estudo, demonstra a inexistência do vínculo laboral e a existência de uma atividade voltada para a formação profissional, prevista e exigida por lei. [... ${ }^{24}$

No mesmo ano, a Terceira Turma do TST decidiu também que a residência médica não configura relação de emprego:

A residência médica é modalidade de ensino de Pós-Graduação, assim definida pelo Decreto no 80.281/77, caracterizada por treinamento em serviço, em regime de dedicação exclusiva, o que dá a falsa impressão de existir relação de emprego. ${ }^{25}$

Fica claro, pelo teor das decisões do Tribunal Superior do Trabalho, que o seu fundamento é legal. As atividades clínicas desenvolvidas pelos médicos residentes são atividades de formação - uma modalidade de ensino - porque a lei assim o define e, portanto, não constituem relação de emprego.

Do mesmo modo, o Tribunal Regional do Trabalho da 4a Região entende que a Justiça do Trabalho, em razão da matéria e por força de determinação legal, não é competente para julgar as causas relativas aos médicos residentes. $O$ fundamento é a

23 BRASÍLIA. Tribunal Superior do Trabalho. Recurso de Revista $n^{\circ} 6380$ (Acórdão $n^{\circ}$ 937), Relator: Min. Orlando Lobato. 10 abr. 1986. D.J. de 09.05.1986.

24 BRASÍLIA. Tribunal Superior do Trabalho, Recurso de Revista ${ }^{\circ} 238$ (Acórdão $n^{\circ}$ 1052), Relator: Min. Guimarães Falcão. 16 abr. 1986. D.J. de 09.05.1986.

25 PORTO ALEGRE. Tribunal Regional do Trabalho da $4^{a}$ Região. Recurso Ordinário 01008-2005-023-04-00-8, Juiz Relator: Hugo Carlos Scheuermann. 14 mar. 2007. Diário Oficial do Estado do RGS - Justiça, 23.03.2007. 
definição determinada pelo Decreto no 80.281/1977 ou pela Lei no 6.932/1981. Conforme o Juiz Hugo Scheuermann:

[...] o Decreto n. 80.281/77, ao definir a residência médica como "modalidade de ensino de pósgraduação destinada a médicos, sob forma de cursos de especialização, [...]", referiu ser a residência médica uma espécie de estágio de alto nível, modalidade de ensino necessária para a complementação do conhecimento acadêmico, não podendo se abstrair do referido texto legal que a relação jurídica que une as partes seja considerada como de trabalho. ${ }^{26}$

A jurisprudência, dentro dessa fundamentação legal, destaca a finalidade educacional da residência médica. Esta é parte da formação médica, é complemento da graduação. Nas palavras da Juíza Ione S. Gonçalves, "a teor da legislação citada, a residência médica é uma atividade de cunho educacional”27.

Assim, o contrato firmado pelo residente é um contrato de matrícula, não de trabalho. Pondera a Juíza Maria Cristina Schaan Ferreira que "de acordo com as legislações citadas, a residência médica tem finalidade educacional, de formação profissional, na forma de curso de especialização" ${ }^{28}$. Do mesmo modo, afirma a Juíza Maria da Graça Ribeiro Centeno que "não se está diante de um contrato de trabalho e sim de um contrato voltado para a formação profissional, no qual o objeto principal é a aprendizagem" 29 .

26 PORTO ALEGRE. Tribunal Regional do Trabalho da $4^{\text {a }}$ Região. Recurso Ordinário 01112-2005-012-04-00-9, Juíza Relatora: Ione Salin Gonçalves. 10 maio 2007. Porto Alegre: Diário Oficial do Estado do RGS - Justiça, 15.05.2007.

27 PORTO ALEGRE. Tribunal Regional do Trabalho da $4^{a}$ Região. Recurso Ordinário 00601-2006-017-04-00-6, Juíza Relatora: Maria Cristina Schaan Ferreira. 13. set. 2007. Diário Oficial do Estado do RGS - Justiça, 24.09.2007.

28 PORTO ALEGRE. Tribunal Regional do Trabalho da $4^{\text {a }}$ Região. Recurso Ordinário 00311-2007-016-04-00-7, Juíza Relatora: Maria da Graça Ribeiro Centeno. 19 jun. 2008. Porto Alegre: Diário Oficial do Estado do RGS - Justiça, 24.06.2008.

29 PORTO ALEGRE. Tribunal Regional do Trabalho da $4^{a}$ Região. Recurso Ordinário 00601-2006-017-04-00-6, Juíza Relatora: Maria Cristina Schaan Ferreira. 13. set. 2007. Diário Oficial do Estado do RGS - Justiça, 24.09.2007. 
A Emenda Constitucional no 45/2004, que alterou o artigo 114 da Constituição Federal e redefiniu a competência da Justiça do Trabalho, ampliando-a de relações de emprego para relações de trabalho. O Tribunal Regional do Trabalho da 4a Região, em várias decisões, entendeu que essa Emenda não muda a situação dos residentes em relação à Justiça do Trabalho, pois não são trabalhadores, são estudantes de pós-graduação. Conforme expõe a Juíza Maria C. Schaan Ferreira, verbis:

Após a EC n45/04, houve divergências quanto ao efetivo alcance da ampliação da competência desta Justiça Especializada para abarcar também as relações de trabalho. Contudo, entende esta relatora que a residência médica não se inclui sequer entre aquelas que se pode considerar abrangida no gênero mais amplo da relação de trabalho. ${ }^{30}$

A fundamentação permaneceu a mesma: a lei forma e os objetivos de educação e aperfeiçoamento profissional. Ressalta a Juíza Maria da Graça R. Centeno.

A residência médica não é, pois, considerada relação de emprego, e nem mesmo pode ser caracterizada como relação de trabalho, prevista no artigo 114 da Constituição Federal, com a redação dada pela Emenda Constitucional 45/2004, que ampliou a competência da Justiça do Trabalho, diante do seu cunho educacional. ${ }^{31}$.

Em consonância com esse ponto de vista, pondera a Juíza Ione S. Gonçalves quanto à residência médica que:

[...] não há como considerá-la relação de emprego e nem mesmo relação de trabalho abrangida pela ampliação de competência introduzida pela Emenda Constitucional 45/2004, precisamente

30 PORTO ALEGRE. Tribunal Regional do Trabalho da $4^{a}$ Região. Recurso Ordinário 00311-2007-016-04-00-7, Juíza Relatora: Maria da Graça Ribeiro Centeno. 19 jun. 2008. Porto Alegre: Diário Oficial do Estado do RGS - Justiça, 24.06.2008.

31 PORTO ALEGRE. Tribunal Regional do Trabalho da $4^{\text {a }}$ Região. Recurso Ordinário 01112-2005-012-04-00-9, Juíza Relatora: Ione Salin Gonçalves. 10 maio 2007. Porto Alegre: Diário Oficial do Estado do RGS - Justiça, 15.05.2007. 
porque afastada por norma legal que lhe dá definição diversa (estágio de residência médica). ${ }^{32}$

Mesmo quando a residência médica não é válida, a natureza do contrato e a intenção educacional da atividade afastam a titularidade à jurisdição trabalhista. De acordo com a Juíza Ione S. Gonçalves, verbis:

Ainda assim, abstraindo-se o fato da validade ou não da residência realizada pelo reclamante junto ao MEC - matéria que, inclusive, foge à competência desta Especializada - tem-se que a relação jurídica havida entre as partes não se revestiu dos requisitos constantes no artigo $3^{\circ}$ da CLT, precisamente porque afastada por norma legal que lhe dá definição diversa (estágio de residência médica), já mencionada precedentemente (Decreto $n^{\circ}$ $80.281 / 77)$. A validade ou não da residência junto ao MEC, por justificativa que até se desconhece, não faz desaparecer a real intenção das partes, que não era o estabelecimento de relação de emprego ou mesmo de simples prestação de serviços. Ademais, a cópia da fl. 46 mostra que o autor, em 31/12/2000, recebeu da reclamada certificado de conclusão de sua residência, e por certo tinha a expectativa de sua validação pelo MEC. ${ }^{33}$

Mesmo frente às decisões dos tribunais trabalhistas, ainda é pertinente uma digressão, dentro do presente artigo, sobre o caráter da residência médica. Afinal, a residência médica não é apenas ensino e aprendizado. Para alcançar seus precípuos fins educacionais, o residente tem de desempenhar atividades produtivas, que implicam tanto em riscos ocupacionais quanto em responsabilidade civil profissional.

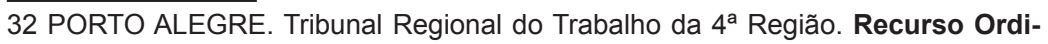
nário 00544-2004-019-04-00-6, Juíza Relatora: Ione Salin Gonçalves. 14. dez. 2005. Diário Oficial do Estado do RGS - Justiça, 06.03.2006.

33 O NLRB é uma agência governamental dos EUA, encarregada de coordenar as relações entre sindicatos e empregadores do setor privado. (Não tem autoridade nas disputar envolvendo servidores e empregados públicos, nem de empregados de ferrovias e de linhas aéreas.) 
A ideia de caráter dual da residência médica, conforme decisão administrativa proferida nos EUA, pode ser elucidativa. Em 1999, o National Labor Relations Board - NLRB (Direção Nacional de Relações de Trabalho) dos EUA ${ }^{34}$ estendeu a proteção das leis federais de trabalho aos médicos residentes de hospitais privados, ao conceder-lhes permissão para sindicalizar$\mathrm{se}^{35}$. James Heinz Jr. observa que em decorrência da decisão, esses médicos residentes passaram a ser reconhecidos não apenas como estudantes, mas também como empregados, e que:

A decisão do NLRB de permitir aos médicos residentes que ingressem em sindicatos tem o potencial de afetar o ambiente no qual os residentes têm atuado. Não é segredo que os médicos residentes estão sujeitos a condições de trabalho assaz desafiadoras. [...] De acordo com Uwe Reinhardt, economista da Universidade de Princeton, o trabalho do residente é "provavelmente a forma mais explorável de trabalho existente". ${ }^{36}$

O ponto de vista de que a residência médica é concomitantemente processo de ensino e aprendizado e de trabalho foi defendida no Brasil por Paulo Elias. ${ }^{37}$ A atividade clínica, contudo, existe na residência médica em função do aprendizado. ${ }^{38}$

34 JAKLEVIC, Mary Chris. Door opens for residents to unionize. NLRB ruling allows house staff at teaching hospitals to bargain collectively; reaction divided. Modern Healthcare, Chicago, v. 29, n. 49, p. 3, Dec. 6, 1999.

35 HEIN, Jr., James G. Employment: NLRB empowers residents to unionize. Journal of Law, Medicine and Ethics, Boston, v. 28, n. 3, p. 307-9, Fall, 2000: p. 307:

The NLRB's decision to allow resident physicians to join labor unions has the potential to affect dramatically the traditional environment in which residents have functioned. It is no secret that resident physicians are subjected to very demanding labor conditions, including regularly working thirty-six hours straight with no sleep. According to Princeton University economist Uwe Reinhardt, resident labor is "probably the most exploitable form of labor there is".

36 ELIAS, Paulo E. M. Residência médica no Brasil: A institucionalização da ambivalência. São Paulo, 1987. Dissertação (Mestrado) Departamento de Medicina Preventiva, Faculdade de Medicina da Universidade de São Paulo.

37 FEUERWERKER, Laura Camargo Macruz. A formação de médicos especialistas e a residência médica no Brasil. Saúde em Debate, Rio de Janeiro, v. 25, n. 57, p. 39-54, 2001.

38 VIETEN, Markus. Berufsplaner Artz : Der Wegweiser. Berlin: Antilla Medizin Verlag, 1996. 
Talvez não seja questão de decidir se residência médica constitui trabalho ou estudo. Não há uma dicotomia necessária entre ambos. Pode-se, sim, pensar que o residente, mesmo sendo pós-graduando, exerce atividades laborais e, portanto, pode ter garantidos direitos trabalhistas. Na República Federal da Alemanha, por exemplo, o especializando tem status de médico assistente, empregado da instituição para a qual presta serviço e da qual recebe supervisão e orientação.

De fato, a Lei 6.932/1981 assegurou aos médicos residentes direito a um dia de folga semanal e a 30 dias consecutivos de repouso por ano de atividade, além de estabelecer que os programas dos cursos de residência médica devem respeitar um limite máximo de 60 horas semanais e de 24 horas de plantão. A Lei $n^{\circ} 7.601 / 1987$, que modificou o art. 4o da Lei 6.932/1981, assegurou aos residentes os direitos previstos na Lei no 3.807/1960 e os decorrentes do seguro de acidentes do trabalho. Deu, ainda, às médica residentes gestantes o direito a quatro meses de afastamento recebendo bolsa de residência. As modificações posteriores do mencionado artigo - as Leis no 8.138/1990 e no 11.381/2006 - mantiveram o teor dessas prerrogativas.

Ora, tais direitos são caracteristicamente afins aos direitos trabalhistas. O seguro contra acidentes de trabalho é previsto no inciso XXVIII do artigo 7º da Constituição Federal da República Federativa do Brasil de 1988 como "direitos dos trabalhadores urbanos e rurais"; repouso semanal está determinado no inciso XV do art. 7º da Constituição e o gozo de féria anuais no inciso XVII. Por fim, o direito de cento e vinte dias (ao invés de quatro meses) de licença à gestante, sem prejuízo da remuneração e do vínculo, está determinado no inciso XVIII do art. 7º da Constituição.

\section{CONSIDERAÇÕES FINAIS}

No início deste estudo perguntamos se os médicos residentes podem ter direitos trabalhistas. A jurisprudência dos 
Tribunais do Trabalho negou a condição tanto de empregado como de trabalhador aos médicos residentes. Estes não têm, portanto, direitos trabalhistas e estão excluídos da prestação jurisdicional do trabalho. As bases desse posicionamento são a definição legal da residência médica e o objetivo de ensino inerente à residência.

Contudo, a própria regulamentação legal da residência médica prevê, para o residente, alguns direitos semelhantes aos de trabalhador: limite de carga horária de atividades, repouso semanal e férias anuais, direitos decorrentes de seguro de acidente de trabalho e, para a residente gestante, licença por quatro meses. Mesmo assim, a reivindicação do cumprimento desses preceitos, quando necessária, tem de ser feita não na Justiça do Trabalho, mas junto à Justiça Comum.

Tendo em conta tais precedentes e considerando que a residência médica tem inerente em si, além do processo de aprendizado, uma sistemática de atividade equivalente à laboral, mudanças tanto na legislação como na jurisprudência podem vir a assegurar aos médicos residentes outros direitos também similares aos laborais. Exemplos de tais possibilidades são o direito a indenização por acidentes de trabalho, o reconhecimento da insalubridade ocupacional, o direito a licença-paternidade e a garantia de respeito ao limite máximo de hora de atividade por semana.

Abstract: Medical residency is the main form of complementing medical education in Brazil. It is a time of at least two years of intense activity associated with considerable load of responsibility. According to Brazilian laws and jurisprudence, residents are students, not workers. Juridical questions and conflicts are, therefore, not of competence of Brazilian Courts of Labour. Nevertheless, several basic rights, equivalent to labour rights, are granted to residents by specific legislation. Brazilian law guarantees to residents one day of rest per week, thirty consecutive days of rest per year of activity, social security, and insurance for 
employment-related accidents. Pregnant female residents have right to a four mouths leave in their residence activity without interruption of grant. Thus, other rights of this nature may hereafter also be extended to residents, such as compensation for occupational accidents, recognition of exposure to occupational hazards, paternity leave, and guarantee of compliance to the limitation of maximum of weekly activity hours.

Key-words: Labour law. Jurisdiction. Medical residency. Medical education. Fundamental rights.

\section{REFERÊNCIAS}

ARAÚJO, Régis de Souza. Parecer / CJ / n. 2324/2000. ASSUNTO: Médico. Contribuição Previdenciária Sobre a Folha de Salários. Direito Previdenciário. Médicos. Contribuição sobre a folha de salários. Brasília: Diário Oficial da União, 07.11.2000. Disponível em http://www.trt02.gov.br/geral/tribunal2/ orgaos/MPAS/PAR2324_00.htm. Acesso em 27.06.2008.

BRASIL. Ministério da Educação. Secretaria de Educação Superior. Residência Médica: Lato sensu. Disponível em: http://portal.mec.gov.br/sesu/index.php? option $=$ content\& task $=$ category\&sectionid $=6 \&$ id $=101 \&$ Itemid $=297$. Acesso em 05.07.2008.

CARNEIRO, Mauro Brandão; GOUVEIA, Valdiney Veloso (coord.). O médico e o seu trabalho: aspectos metodológicos e resultados do Brasil. Brasilia: Conselho Federal de Medicina, 2004.

CARRO, Adriana Rosa Linhares; ARAÚJO, Aniara Nascimento Corrêa; OLIVEIRA Filho, Nosor Orlando de; SEIXAS, Paulo Henrique D`Ângelo. Residência médica: prioridades do Sistema Único de Saúde que determinam a distribuição de vagas. In: BARROS, André Falcão e col. (org.). Observatório de Recursos Humanos em Saúde no Brasil. Brasilia: Ministério da Saúde \& OPAS, 2004: p. 223-236.

CONSELHO FEDERAL DE MEDICINA. Processo-Consulta CFM n ${ }^{\circ}$ 0913/1991. Responsabilidade ética do médico residente por atos médicos realizados. Relator: Cons. Hilário Lourenço de FREITAS Júnior. Brasília: CFM, 08. nov. 1991 (Aprovado em sessão plenária dia 16.01.1992). Disponível em http://www.portalmedico.org.br/pareceres/cfm/1992/3_1992.htm. Acesso em 06.07.2008. 


\section{CONSELHO REGIONAL DE MEDICINA DO ESTADO DE SÃO}

PAULO. Parecer no 101.724/2002. Direitos e deveres do Médico Residente. Relatora: Cons. Irene ABRAMOVICH. São Paulo: CREMESP, aprovado em reunião plenária de 30.11.2002 e homologado em reunião plenária, de 03.12.2002. Disponível em http://www.bioetica.org.br/legislacao/res_par/ integra/101724_02.php. Acesso em 08.06.2008.

ELIAS, Paulo E. M. Residência médica no Brasil: A institucionalização da ambivalência. São Paulo, 1987. Dissertação (Mestrado) Departamento de Medicina Preventiva, Faculdade de Medicina da Universidade de São Paulo.

FEUERWERKER, Laura Camargo Macruz. A formação de médicos especialistas e a residência médica no Brasil. Saúde em Debate, Rio de Janeiro, v. 25 , n. 57 , p. $39-54,2001$.

FEUERWERKER, Laura Camargo Macruz; SENA, Roseni R. Contribuição ao movimento de mudança na formação dos profissionais de saúde: uma avaliação das experiências UNI. Interface: Comunicação, Saúde e Educação, Botucatu, v. 6, n. 10, p. 37-50, 2002.

FLEXNER, Abraham. Medical education in the United States and Canada: a report to the Carnegie Foundation for the Advancement of Teaching. Bull 4. New York: The Carnegie Foundation; 1910.

FISZBEYN, Celso. A residência médica como formadora de recursos humanos para o Sistema de Saúde no Estado de São Paulo: uma visão crítica. São Paulo, 2000. Dissertação (Mestrado) Departamento de Prática de Saúde Pública, Faculdade de Saúde Pública da Universidade de São Paulo.

FRAGA Filho, Clementino. Ensino médico no Brasil: análise crítica. Arquivos de Gastroenterologia, São Paulo, v. 25, n. especial, p. 26-31, 1988.

HEIN, Junior, James G. Employment: NLRB empowers residents to unionize. Journal of Law, Medicine and Ethics, Boston, v. 28, n. 3, p. 307-9, Fall 2000.

JAKLEVIC, Mary Chris. Door opens for residents to unionize. NLRB ruling allows house staff at teaching hospitals to bargain collectively; reaction divided. Modern Healthcare, Chicago, v. 29, n. 49, p. 3, Dec. 6, 1999.

KFOURI Neto, Miguel. Culpa médica e ônus da prova. São Paulo: Revista dos Tribunais, 2002.

KLAIMAN, Miriam H. Medical education's dirtiest secret: Use of medical residents. Humanist, v. 63, Nov.Dec. 2003. 
KOIFMAN, Lilian. Crítica ao modelo biomédico na reformulação curricular do curso de medicina da Universidade Federal Fluminense. Rio de Janeiro, 1996. Dissertação (Mestrado), Escola Nacional de Saúde Pública.

LANDRIGAN, Christopher P.; ROTHSCHILD Jeffrey M.; CRONIN John W. et al. Effect of reducing interns' workhours on serious medical errors in intensive care units. New England Journal of Medicine, Waltham (MA), v. 351, p. 1838-1848, 28 Oct. 2004.

MARQUES, Heloisa Helena de Sousa; RODRIGUES, Laura Cunha. A luta pelos direitos trabalhistas dos médicos residentes. Pediatria, São Paulo, v. 1, p. 40-44, 1979.

MASSUDA, Adriano; CUNHA, Francisco Mogadouro da; PETTA, Helena. Residência médica: contribuições dos médicos residentes ao debate. Revista da Associação Médica Brasileira, São Paulo, v. 53, n. 2, p. 96-97, mar./abr. 2007.

McKUSICK, Victor A. Foreword. In: NILSSON, Kent R.; PICCINI, Jonathan. The Osler Medical Handbook / Osler Medical Service, Johns Hopkins Hospital. 2. ed. Philadelphia: Elsevier, 2006: p. ix-xi.

MORAES, Irany Novah. Erro médico e a justiça. 5. ed. São Paulo: Revista dos Tribunais, 2004.

NOGUEIRA-MARTINS, Luiz Antônio; JORGE, Miguel Roberto. Natureza e magnitude do estresse na Residência Médica. Revista da Associação Médica Brasileira, São Paulo, p. 28-34, jan./fev. 1998, v. 44, n. 1.

PESSOA, José Hugo de Lins; CONSTANTINO, Clóvis Francisco. Revista da Sociedade de Cardiologia do Estado de São Paulo, São Paulo, v. 12, n. 6, p. 821-825, nov./dez., 2002.

PRUNES, José Luiz Ferreira. Direito do Trabalho para médicos e dentistas. Rio de Janeiro: Edições Trabalhistas, 1975.

RAE, Angus. Osler vindicated: the ghost of Flexner laid to rest. Canadian Medical Association Journal, Ottawa, v. 164, n. 3, p. 1860-1861, 26 Jun. 2001.

SOUZA, Néri Tadeu Câmara. Responsabilidade civil e penal do médico. 2 . ed. Campinas: LZN, 2006.

UNIFESP. Departamento de Psiquiatria. Núcleo de Assistência e Pesquisa em Residência Médica. Os fundamentos para a criação do serviço e o relato da experiência de um ano. São Paulo, UNIFESP: 23.10.2001. Disponível em: http://www.unifesp.br/dpsiq/grupos/napreme.htm, acesso em 13.07.2008.

VIETEN, Markus. Berufsplaner Artz: Der Wegweiser. Berlin: Antilla Medizin Verlag, 1996. 


\section{Legislação}

BRASIL. Constituição da República Federativa do Brasil, de 05 de outubro de 1988.

BRASIL. Decreto n. 80.281, de 5 de setembro de 1977.

BRASIL. Lei n. 6.932, de 7 de julho de 1981.

BRASIL. Lei n. 7.601, de 15 de maio de 1987.

BRASIL. Lei n. 8.138, de 28 de dezembro de 1990.

BRASIL. Lei n. 11.381, de 1º de dezembro de 2006.

\section{Jurisprudência}

BRASÍLIA. Tribunal Superior do Trabalho. Recurso de Revista no 2120 (Acórdão no 3376). Relator: Min. Ildélio Martins. 24 set. 1984. Brasília: Diário da Justiça da União, 14.12.1984.

BRASÍLIA. Tribunal Superior do Trabalho. Recurso de Revista ${ }^{\circ} 6380$ (Acórdão no 937), Relator: Min. Orlando Lobato. 10 abr. 1986. Brasília: Diário da Justiça da União, 09.05.1986.

BRASÍLIA. Tribunal Superior do Trabalho, Recurso de Revista $\mathbf{n}^{\circ} 238$ (Acórdão no 1052), Relator: Min. Guimarães Falcão. 16 abr. 1986. Brasília: Diário da Justiça da União, 09.05.1986.

PORTO ALEGRE. Tribunal Regional do Trabalho da 4a Região. Recurso Ordinário 00544-2004-019-04-00-6, Juíza Relatora: Ione Salin Gonçalves. 14 dez. 2005. Porto Alegre: Diário Oficial do Estado do RGS - Justiça, 06.03.2006.

PORTO ALEGRE. Tribunal Regional do Trabalho da 4a Região. Recurso Ordinário 00086-2005-002-04-00-4, Juiz Relator: Milton Varela Dutra. 16 mar. 2006. Porto Alegre: Diário Oficial do Estado do RGS - Justiça, 29.03.2006.

PORTO ALEGRE. Tribunal Regional do Trabalho da 4a Região.

Recurso Ordinário 01008-2005-023-04-00-8, Juiz Relator: Hugo Carlos Scheuermann. 14 mar. 2007. Porto Alegre: Diário Oficial do Estado do RGS - Justiça, 23.03.2007.

PORTO ALEGRE. Tribunal Regional do Trabalho da 4a Região. Recurso Ordinário 01112-2005-012-04-00-9, Juíza Relatora: Ione Salin Gonçalves. 10 maio 2007. Porto Alegre: Diário Oficial do Estado do RGS - Justiça, 15.05.2007.

PORTO ALEGRE. Tribunal Regional do Trabalho da 4a Região. Recurso Ordinário 00601-2006-017-04-00-6, Juíza Relatora: Maria Cristina Schaan Ferreira. 13 set. 2007. Porto Alegre: Diário Oficial do Estado do RGS Justiça, 24.09.2007.

PORTO ALEGRE. Tribunal Regional do Trabalho da $4^{a}$ Região. Recurso Ordinário 00311-2007-016-04-00-7, Juiza Relatora: Maria da Graça Ribeiro Centeno. 19 jun. 2008. Porto Alegre: Diário Oficial do Estado do RGS Justiça, 24.06.2008. 